\title{
Neurobiology of anesthetic-surgical stress and induced behavioral changes in dogs and cats: A review
}

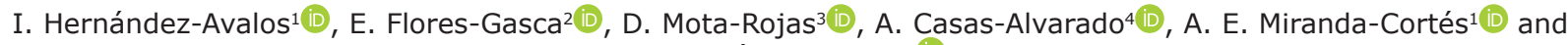 \\ A. Domínguez-Oliva1 ${ }^{1}$
}

\begin{abstract}
1. Department of Biological Sciences, Clinical Pharmacology and Veterinary Anesthesia, Faculty of Higher Studies Cuautitlán, Universidad Nacional Autónoma de México, State of Mexico 54714, Mexico; 2. Department of Veterinary Surgery, Faculty of Higher Studies Cuautitlán, Universidad Nacional Autónoma de México, State of Mexico 54714, Mexico; 3. Neurophysiology of Pain, Behavior and Assessment of Welfare in Domestic Animals, DPAA, Universidad Autónoma Metropolitana, Mexico City 04960, Mexico; 4. Master in Agricultural Sciences. Animal Welfare, Universidad Autónoma Metropolitana, Mexico City 04960, Mexico.

Corresponding author: I. Hernández-Avalos, e-mail: mvziha@hotmail.com

Co-authors: EF: enfloga12@yahoo.com.mx, DM: dmota100@yahoo.com.mx, AC: ale0164g@hotmail.com, AEM: kujaku_ou@hotmail.com, AD: mvz.freena@gmail.com

Received: 24-08-2020, Accepted: 08-01-2021, Published online: 11-02-2021
\end{abstract}

doi: www.doi.org/10.14202/vetworld.2021.393-404 How to cite this article: Hernández-Avalos I, Flores-Gasca E, Mota-Rojas D, Casas-Alvarado A, Miranda-Cortés AE, Domínguez-Oliva A (2021) Neurobiology of anesthetic-surgical stress and induced behavioral changes in dogs and cats: A review, Veterinary World, 14(2): 393-404.

\begin{abstract}
The anesthetic-surgical stress response consists of metabolic, neuroendocrine, hemodynamic, immunological, and behavioral adaptations through chemical mediators such as the adrenocorticotropic hormone, growth hormone, antidiuretic hormone, cortisol, aldosterone, angiotensin II, thyroid-stimulating hormone, thyroxine, triiodothyronine, follicle-stimulating hormone, luteinizing hormone, catecholamines, insulin, interleukin (IL)-1, IL-6, tumor necrosis factor-alpha, and prostaglandin E-2. Behavioral changes include adopting the so-called prayer posture, altered facial expressions, hyporexia or anorexia, drowsiness, sleep disorders, restriction of movement, licking or biting the injured area, and vocalizations. Overall, these changes are essential mechanisms to counteract harmful stimuli. However, if uncontrolled surgical stress persists, recovery time may be prolonged, along with increased susceptibility to infections in the post-operative period. This review discusses the neurobiology and most relevant organic responses to pain and anesthetic-surgical stress in dogs and cats. It highlights the role of stress biomarkers and their influence on autonomous and demeanor aspects and emphasizes the importance of understanding and correlating all factors to provide a more accurate assessment of pain and animal welfare in dogs and cats throughout the surgical process.
\end{abstract}

Keywords: cats, dogs, neurobiology, pain, stress, welfare.

\section{Introduction}

Stress is defined as an unconscious response to tissue damage. It may manifest as autonomic, metabolic, hormonal, immunological, and neuroendocrine changes provoked by injury or trauma $[1,2]$. When an organism's central nervous system (CNS) perceives a potentially harmful stimulus, it responds through defense mechanisms that involve modifications of both behavior and the autonomic nervous system to restore homeostasis. This process is characterized by activation of the hypothalamic-pituitary-adrenal axis (HPA) and the sympathetic nervous system (SyNS), along with an increase in the concentrations of adrenocorticotropic hormone $(\mathrm{ACTH})$ and cortisol $[3,4]$.

The consequences of prolonged exposure to stressors include sensitization to pain, longer post-surgical recovery, and in some cases, sepsis, or delays in healing [5]. After surgical intervention, central stimulation

Copyright: Hernández-Avalos, et al. Open Access. This article is distributed under the terms of the Creative Commons Attribution 4.0 International License (http://creativecommons.org/licenses/ by/4.0/), which permits unrestricted use, distribution, and reproduction in any medium, provided you give appropriate credit to the original author(s) and the source, provide a link to the Creative Commons license, and indicate if changes were made. The Creative Commons Public Domain Dedication waiver (http:// creativecommons.org/publicdomain/zero/1.0/) applies to the data made available in this article, unless otherwise stated. is triggered through afferent nerve fibers that activate both the HP and sympathetic-adrenal-medullary axes [6], both of which transmit information to the paraventricular nucleus (NPV) of the hypothalamus through a network that includes areas of the amygdala, the nucleus of the bed of the stria terminalis, and the prefrontal cortex $[7,8]$. The NPV initiates the sequence of events by secreting corticotropin-releasing hormone (CRH) and vasopressin (VP) into the hypothalamic portal system, which induces $\mathrm{ACTH}$ production in the adenohypophysis with the subsequent stimulation of receptors in the fascicular area of the adrenal cortex to release glucocorticoids, mainly cortisol and corticosterone, into the bloodstream. Together, these events constitute the "fight-or-flight" response and the basis of the neurobiology of acute pain $[9,10]$.

This review discusses the basic neurobiology and physio-metabolic outcomes in dogs and cats that suffer acute pain caused by surgical trauma. Highlighting the role of stress biomarkers and their influence on autonomic and behavioral aspects, emphasizing the importance of understanding and correlating all factors to provide a more accurate assessment of pain and animal welfare in dogs and cats throughout the surgical process. 


\section{Concept of Surgical Stress}

Surgical stress has been defined as "the biological response to factors that alter or threaten homeostasis." The main stressors associated with surgical procedures are physical (e.g., tissue damage, impingement, and perception of pain) and chemical (application of antiseptics to the affected area) factors that promote specific reactions as a compensatory mechanism to prevent secondary damage and increase the availability of the substrates that essential organs require $[6,11]$. This process generates physiological changes that correlate with stressful states and/or disease [12].

Some authors consider that surgical lesions are accompanied by a series of specific reactions as a compensatory mechanism to prevent secondary damage and increase the availability of the substrates that essential organs require. This process generates physiological changes that correlate with stressful states [6].

Certain studies suggest that applying any anesthetic can potentially modify physiological responses to surgical procedures due to (i) hypnosis induced; (ii) alterations of the organic functions of the cardiovascular, respiratory, digestive, and neuroendocrine systems; (iii) metabolic changes; and (iv) affectations of immunological homeostasis since the endocrine, nervous, and immunological processes involved have physically and functionally related interactions [6,13-15].

\section{Neuroendocrine Response of the HPA}

One consequence of activation of the HPA is a greater secretion of catabolic hormones. This triggers a cascade of metabolic processes that degrade proteins, fats, and carbohydrates $[1,12,16]$. This cascade may contribute to the development of hypovolemia and painful states that can set off a systemic, post-trauma neuroendocrine response by stimulating the efferent neurons around the wound site $[8,17]$. This response is characterized by the pituitary glands increase in hormone secretion and activation of the SyNS. The ACTH, growth hormone $(\mathrm{GH})$, and antidiuretic hormone (cortisol and aldosterone) concentration levels increase, while the effects of others, such as thyroid-stimulating hormone (TSH), follicle-stimulating hormone (FSH), and luteinizing hormone (LH), may increase or decrease during neuroendocrine control (Figure-1) [1,8,14,16].

These changes aim to maintain an adequate volume of fluids in the body by counteracting the effect of the renin secreted by the juxtaglomerular cells as a reflex reaction to efferent sympathetic stimulation [1]. Renin and angiotensin-converting enzyme act on their respective substrates to produce the active form called angiotensin II, which raises blood pressure through arteriolar vasoconstriction and by stimulating aldosterone secretion to restore circulatory volume during hypovolemic states [14].

Plasma VP exerts a similar action during hypotension by causing reabsorption of $\mathrm{Na}+$ and water,

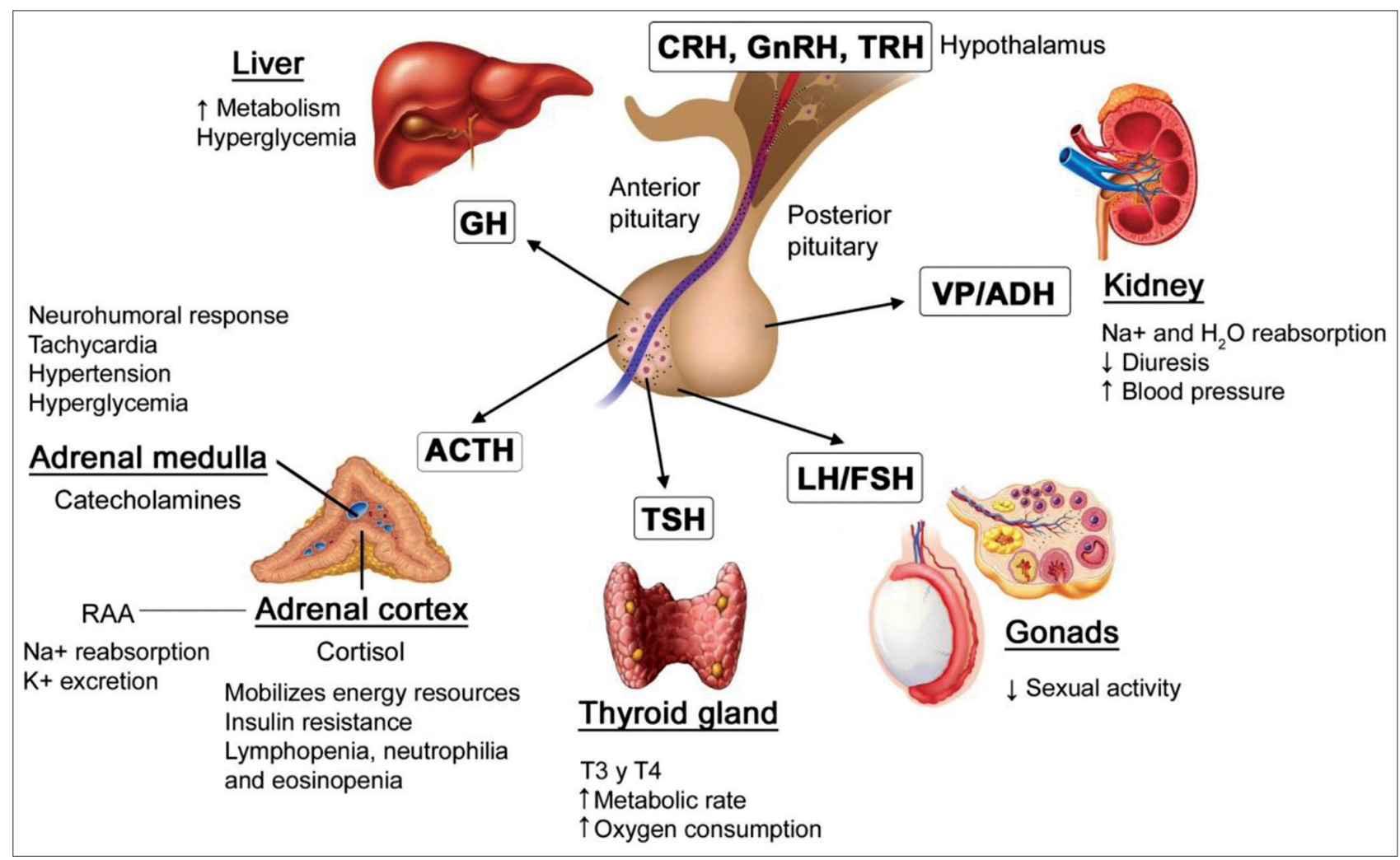

Figure-1: The hypothalamic-pituitary-adrenal axis and the response to surgical stress. ACTH=Adrenocorticotropic hormone, $\mathrm{CRH}=$ Corticotropin-releasing hormone, $\mathrm{FSH}=$ Follicle-stimulating hormone, $\mathrm{GH}=\mathrm{Growth}$ hormone, GnRH=Gonadotropinreleasing hormone, $\mathrm{K}+=$ Potassium, $\mathrm{LH}=$ Luteinizing hormone, $\mathrm{Na}+=$ Sodium, RAA=Renin-angiotensin-aldosterone, $\mathrm{TRH}=$ Thyrotropin-releasing hormone, $\mathrm{TSH}=$ Thyroid-stimulating hormone, VP=Vasopressin [Source: $1,8,14,16]$. 
which decreases urine production and increases systolic blood pressure and mean arterial pressure (MAP). This hemodynamic regulation correlates with the degree of pain after stretching of the ovarian pedicle and soft-tissue management $[18,19]$. Neurosecretion of VP that goes on for 3-5 days, depending on the severity of surgical damage, is associated with complications in the immediate post-operative period [20,21].

\section{Role of Thyroid Hormones in Surgical Stress}

The most important thyroid hormones are thyroxine $\left(\mathrm{T}_{4}\right)$ and triiodothyronine $\left(\mathrm{T}_{3}\right)$. Their secretion is controlled by the TSH [1]. Together with catecholamines (epinephrine and norepinephrine), these hormones stimulate oxygen consumption in most metabolically active tissue, except for organs such as the brain, spleen, and anterior part of the pituitary gland. $\mathrm{T}_{4}$ and $\mathrm{T}_{3}$ help regulates the metabolic rate by increasing the absorption of carbohydrates from the intestine and stimulating the central (CNS) and peripheral nervous system [22]. However, these hormones are suppressed by both exogenous and endogenous corticosteroids during surgery [23].

\section{Relationship of Catecholamines to Surgical Stress}

Stimulation of the SyNS by anesthetic drugs or acute perioperative pain produces secretion of the corticotropin-releasing factor (CRF), which stimulates the release of ACTH. The main role of ACTH is to activate the adrenal cortex so that it secretes cortisol, corticosterone, and aldosterone. This mechanism is involved in the excretion of catecholamines during surgery after stimulation of the adrenomedullary region, playing an important role in the neurohumoral modulation of stress and nociception [11,24].

Other studies have shown that the actions of these neurotransmitters are controlled by the activation or stimulation of $\alpha$-adrenergic receptors (sub-divided into $\alpha_{1 \mathrm{~A}}, \alpha_{1 \mathrm{~B}}, \alpha_{1 \mathrm{D}}, \alpha_{2 \mathrm{~B}}$, and $\alpha_{2 \mathrm{C}}$ ) or $\beta$-adrenergic (sub-divided into $\beta_{1}, \beta_{2}$, and $\beta_{3}$ ) that are found in catecholaminergic neurons [25]. Both types are sensitive to epinephrine and norepinephrine, but the responses they induce differ with the tissue and number of receptors present [21]. The main metabolic effect is performed by $\beta$, receptors as they increase glycemia by promoting glycogenolysis and gluconeogenesis of hepatic and muscular origin. During stress, no glucose-6-phosphatase is available, so muscular tissue produces lactate instead of glucose. However, if the harmful stimulus does not persist, the liver will re-convert the lactate into glucose [6].

Cardiovascular effects such as hypertension and tachycardia occur when catecholamines interact with the $\alpha_{2}$ receptors that modulate the release of norepinephrine in the post-synaptic nerve endings as a result of epinephrine secretion in the adrenal medulla. This process affects the adenylyl cyclase system to increase cardiac contractility [26]. Finally, these receptors have been identified as components of the pain modulating pathway because the $\alpha_{2}$ type can inhibit adrenergic impulses [25].

\section{Cortisol}

Cortisol is produced by the adrenal cortex. Its serum concentration increases in the perioperative period due to the release and stimulation of ACTH. High concentrations of both hormones were found during the immediate post-operative period when intraoperative analgesia was insufficient [27]. In addition, its ratio has been shown to be a clinical marker to detect adrenal response due to stress in pathologies such as feline idiopathic cystitis [28].

The primary metabolic effect of cortisol is mobilizing energy. Cortisol inhibits the use of glucose by cells in a reaction influenced by an apparent resistance to insulin. This is related to the direct response of $\beta$ cells in the pancreas, which promotes gluconeogenesis in the liver and the use of glucose by somatic cells [29].

In the liver, glucocorticoids facilitate the ability to concentrate amino acids from extra-hepatic tissue (skeletal muscle) for subsequent degradation. This occurs because cortisol significantly enhances hepatic glutamic-pyruvic transaminase activity and subsequently increases the transamination of alanine to pyruvate and then lactate [26]. The release of catecholamines also increases the amount of pyruvate available for its later transformation into glucose [30].

In combination with catecholamines and $\mathrm{GH}$, cortisol contributes to lipid metabolism by promoting the conversion of triglycerides into glycerol and fatty acids. These metabolites act as an important energy source in the perioperative period and are utilized for gluconeogenesis and eliminating fatty acids during ketogenesis. Fatty acids can be oxidized in the liver and muscle to be converted into ketone bodies or re-esterified [16,31].

\section{Related Gonadotropic Hormones: FSH, LH, and Testosterone}

Sex steroids are known mainly for their role in fertility and reproduction, but during stressful events, they are also mediated by the HPA when it recognizes a nociceptive stimulus $[32,33]$. The effects of gonadocorticoids vary, but, in general, testosterone, LH, and FSH concentrations decrease during the first 5 post-operative days $[32,34,35]$.

\section{GH}

Like glucocorticoids, this hormone contributes to hyperglycemia by stimulating glucose production, but it also has an anti-insulin effect that inhibits glucose uptake and its use by somatic cells. GH activity differs from that of other hormones, such as cortisol and catecholamines, which stimulate gluconeogenesis and glycogenolysis for the subsequent generation 
of glucose, which eventually serves as an energy source [8]. Moreover, it creates energy reserves for high energy demand organs, such as neurons, under hypoglycemia conditions [36,37].

\section{Other Alterations Associated with the Neuroendocrine Response}

\section{Glucose, glucagon, and insulin}

In general, catecholamines and cortisol in the bloodstream enhance glycogenolysis and gluconeogenesis to increase glucose concentrations during the trans-surgical interval. "Stress hyperglycemia" is sometimes confused with diabetes in felines [38]. However, when it is a mere consequence of stress, it is associated with behavioral changes such as aggression or reluctance to handling [39]. Hyperglycemia persists due to the action of catabolic hormones and lowers insulin activity; the latter is reported as a key hormone for anabolism [1]. There are reports that insulin is a key hormone for anabolism, as it is synthesized in pancreatic $\beta$-cells after eating or when blood glucose and amino acid levels rise. GH promotes glucose uptake from striated skeletal muscle and adipose tissue through the conversion of glucose and triglycerides. In addition, it stimulates the formation of glycogen from glucose in the liver [40].

Both the induction of anesthesia and surgical stimulation cause insulin resistance due to the activation of $\alpha$-adrenergic receptors and the inhibition of pancreatic $\alpha$-cells to equalize catabolism in response to hyperglycemia $[36,41]$.

Glucagon is another product secreted by pancreatic $\beta$ cells that may occur at higher levels after major surgical interventions. This mediator stimulates hepatic glycogenolysis, increases gluconeogenesis from amino acids in the liver, and controls lipolytic activity. There is still wide debate on its effects because observations have shown that it does not contribute significantly to the hyperglycemic response [42].

\section{Lactate}

After gluconeogenesis or glycogenolysis, a molecule of glucose through anaerobic glycolysis is transformed into two molecules of pyruvate to generate two molecules of adenosine triphosphate (ATP) that produces energy. Pyruvate can follow two metabolic pathways: In the presence of oxygen, it enters the Krebs cycle and creates 36 ATP molecules. In contrast, when the availability of blood oxygen is insufficient, or when the capacity of the pyruvate dehydrogenase enzyme is exceeded, it results in the creation of lactate, a biofuel present in the skeletal muscles, brain, heart, kidney, and liver [29,43,44].

Thus, lactate and hyperlactatemia can be considered reliable biomarkers of hypoxia, hypoperfusion, and anaerobic glycolysis [45], and its presence is indicative of an accelerated state of glycolysis posterior to SyNS activation to ensure a sufficient supply of bioenergy [46]. However, hyperlactatemia has also been reported with strenuous exercise [47] or mountain climbing where oxygen input is low. Hyperlactatemia is not a necessary condition, even though $\mathrm{pO}_{2}$ values of $25 \mathrm{mmHg}$ have been reported. A similar situation has been described in patients with sepsis [48]. GarciaAlvarez et al. [45] suggested that hyperlactatemia should not be seen as a biomarker of hypoxia or anaerobic glycolysis but rather as a major component of the stress response during activation of the HPA.

\section{Cardiovascular Changes associated with the Neuroendocrine Response}

Recent work has shown that hypertension and tachycardia reflect SyNS activity after nociceptive stimulus caused by trauma or stress $[1,14,30]$. This was evaluated during elective ovariohysterectomy in bitches, where increased heart rate and blood pressure were observed when the harmful stimulus was most intense [20].

Thrasher et al. [49] described high concentrations of plasma VP after a period of hypotension in the presence of harmful stimuli. This hormone is a neuropeptide that can be altered by high adrenal corticosteroid levels, so its presence determines the duration of the effects of corticosteroids. VP acts on kidneys and the juxtaglomerular cells, promoting water retention and concentrated urine associated with surgical trauma, hypovolemia, and activation of pressure and volume receptors in the CNS $[49,50]$.

Another mechanism in the kidney is the stimulation of juxtaglomerular cells. These cells synthesize, store, and secrete renin, the enzyme that catalyzes angiotensin II production and, subsequently, the release of aldosterone into the adrenal cortex, which is responsible for promoting the reabsorption of $\mathrm{Na}+$ and water in the distal tubules, which means that it participates in regulating the blood [51].

During surgical procedures, blood oxygen pressure $\left(\mathrm{SaO}_{2}\right.$ and $\left.\mathrm{SpO}_{2}\right)$ decreases. This is most evident when patients do not receive pre-oxygenation, which triggers a decrease in oxidative metabolism with the activation of the anaerobic glycolysis pathway. Here, lactic acid accumulation and the development of lactic acidemia increase progressively, causing intracellular damage and cell death. In the post-operative period, the effects of hypoperfusion and hypoxia as causes of reduced blood flow become more evident, while high lactate levels, metabolic acidosis, and increased free fatty acids are also present [16].

\section{Immune Response}

After a harmful event, such as a surgical procedure, the immune system may be either activated or depressed according to the type of stress-induced. This response is mediated by immunological mediators such as cytokines or interleukins (ILs), low molecular weight proteins produced by the activity of leukocytes, fibroblasts, and endothelial cells [52]. Cytokines cause pro-inflammatory responses. They include IL-1, IL-6, and tumor necrosis factor-alpha (TNF- $\alpha$ ), which have an effect on metabolism and play a key role in 
regulating cardiovascular, endocrine, and neuronal activity [53]. IL-1 is a cytokine synthesized by monocytes and leukocytes into two isoforms (IL- $\alpha$ and IL- $\beta$, predominantly the $\beta$ isoform) that perform a regulatory function of myelopoiesis [54]. It is considered an endogenous pyrogen that raises body temperature and increases prostaglandin E-2 synthesis, whose action on the hypothalamus causes fever and anorexia [55].

TNF- $\alpha$, in turn, is produced by monocytes, macrophages, Kupffer cells, mast cells, and lymphocytes [56] and is related to metabolic effects. This is due to increased transmembrane glucose transport and glycolysis function that, together with IL-1, promote the proteolysis of skeletal muscle and the release of amino acids by producing serum iron and zinc deficiency through the release of the protein to which these minerals tend to bind. Thus, these cytokines contribute to states of deep anorexia and the development of cachexia [52]. In addition, prolonged exposure to excessive concentrations of these two cytokines has a negative inotropic effect on the myocardium that can cause left ventricular dysfunction, increase nitric oxide levels, and promote vasodilation [56].
IL-6, which is biosynthesized by monocytes and macrophages, has been detected in cerebrospinal and synovial fluids during bacterial and viral infections of the CNS and inflammatory arthritis $[52,57]$. In contrast to IL- 1 and TNF- $\alpha$, the participation of IL- 6 depends on the magnitude of the tissue injury and control of the immune response. Its plasma concentration increases rapidly in patients undergoing surgery, but the secretion rate can be influenced by anesthetic drugs and endogenous corticosteroid levels (Figure-2). Experimental evidence suggests that controlling the immune system and its mediators may mitigate the consequences of traumatic injuries and, hence, decrease perioperative morbidity and mortality [51]. Table-1 summarizes the main immunomodulatory effects of some sedatives [58-79], local analgesics, and anesthetics commonly used in dogs and cats.

\section{Involvement of Glucocorticoids in the Immune Response}

Glucocorticoids produce a "stress leukogram" characterized by eosinopenia due to intravascular lysis, sequestration in the liver and spleen, decreased release from bone marrow, and migration to the lymphoid tissues that generate glucocorticoids. Lymphopenia is

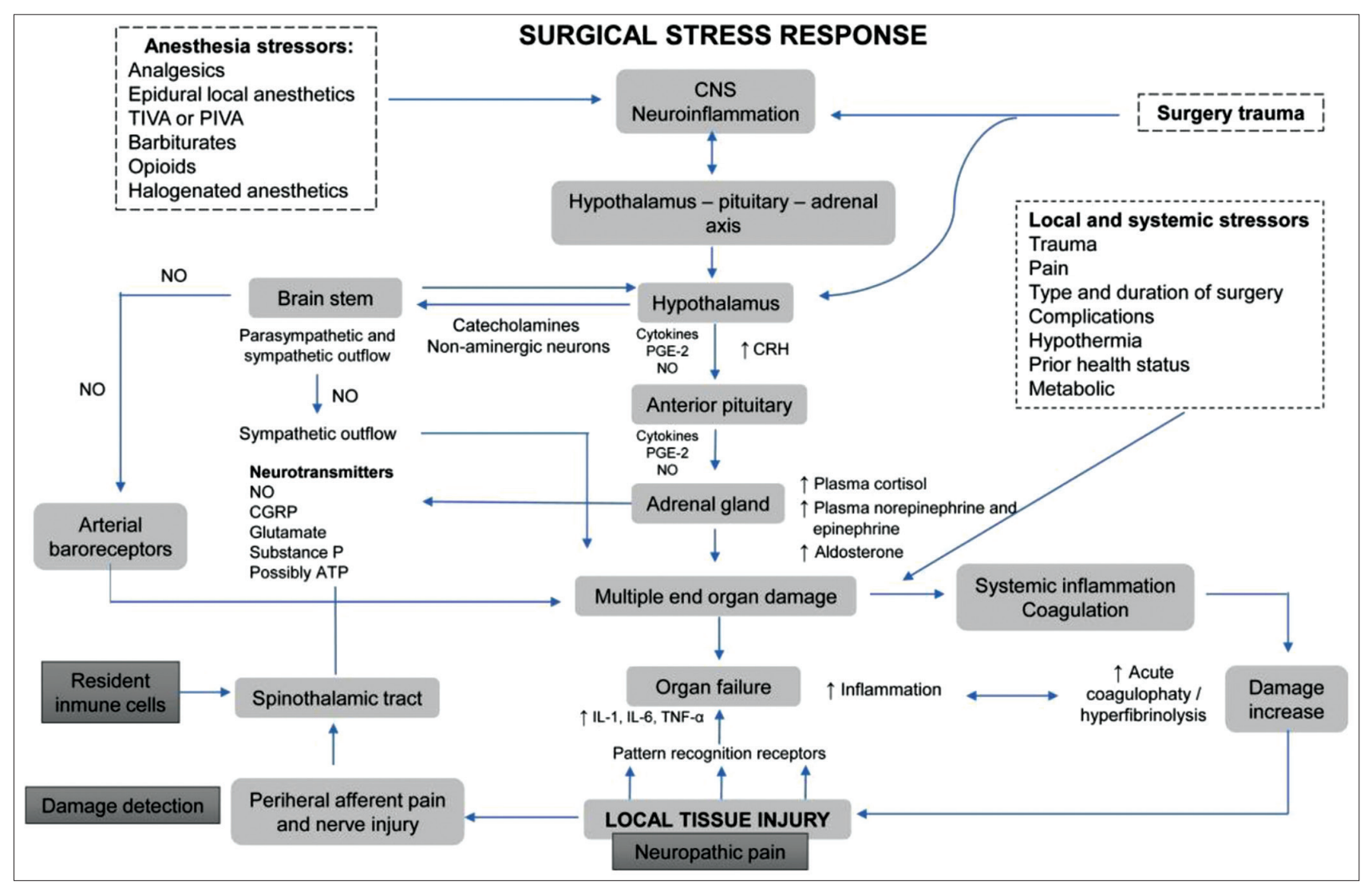

Figure-2: Schematic of the neurobiological interaction between the hypothalamic-pituitary-adrenal axis, the metabolic changes, and the immune system after anesthetic-surgical stimuli. CNS=Central nervous system, CGRP=Calcitonin genrelated peptide, $\mathrm{CRH}=$ Corticotrophin-releasing hormone, IL=Interleukin, $\mathrm{NO}=$ Nitric oxide, PIVA=Partial intravenous anesthesia, PGE=Prostaglandin, TIVA=Total intravenous anesthesia, TNF=Tumor necrosis factor. Surgical stress, caused by tissue injury or anesthetic drugs, activates the HPA and hence the release of catecholamines and cortisol (known as stress hormones) in the adrenal gland. This action is controlled by factors such as CRH, VP, and ACTH in the pituitary gland. Under pathological states or persistent pain, the enhanced activity of cytokines (IL, TNF-a), PG, and NO can contribute to ischemia, inflammation, and coagulopathies. Together with the neurotransmitters coming from the CNS and spinal cord, this may result in additional damage [Source: $1,3,5,53,56,58]$. 
Table-1: Immunomodulatory effects of the most commonly used sedatives, local analgesics, and anaesthetics for dogs and cats.

\begin{tabular}{|c|c|c|}
\hline Drug & Immunomodulatory effects & References \\
\hline \multirow[t]{2}{*}{ Acepromazine } & Antioxidant effect decreases ROS. & [58] \\
\hline & Oxidation-reduction reactions are reduced in bacteria like Mycobacterium spp. & [59] \\
\hline \multirow[t]{2}{*}{ Dexmedetomidine } & $\begin{array}{l}\text { Modulation of } \mathrm{TLR}_{4} \text { and NFjB, pro-inflammatory cytokines decrease. Phagocytosis is } \\
\text { stimulated. }\end{array}$ & {$[60]$} \\
\hline & Reduces $\mathrm{TNF}_{a^{\prime}}$ TLR, and IL-6. & {$[62]$} \\
\hline \multirow[t]{4}{*}{ Ketamine } & NK cells, neutrophil chemotaxis, macrophages, and cytokines are suppressed. & [63] \\
\hline & Thromboxane $B 2$, TNF $_{a}, \mathrm{IL}-1 \beta$, and IL- 6 are reduced. & [64] \\
\hline & Stabilizes the release of $\mathrm{TLR}_{4}$ and NFjB. & [65] \\
\hline & & {$[66]$} \\
\hline \multirow{2}{*}{ Lidocaine } & Reduces phagocytes, neutrophil adhesion, ROS, and PG production. & [67] \\
\hline & Stabilization of endothelial membrane. & {$[68]$} \\
\hline \multirow{3}{*}{ Midazolam } & Has an anti-inflammatory and immunosuppressive effect. & {$[70]$} \\
\hline & Decreases COX and iNOS, phagocytes. Lymphocyte proliferates and there is an & [71] \\
\hline & alteration in neutrophil apoptosis. & {$[72]$} \\
\hline \multirow[t]{3}{*}{ Morphine } & Interferes with antigen presentation; increases lymphocyte apoptosis and alters & [73] \\
\hline & B lymphocytes differentiation. Reduced phagocytosis and NK activity. Activates T & [74] \\
\hline & lymphocytes. & [75] \\
\hline \multirow[t]{2}{*}{ Propofol } & The antioxidant effects of PGE2 decrease. & [76] \\
\hline & $\begin{array}{l}\text { Inhibits neutrophil and macrophage phagocytosis, as well as ROS production. NK } \\
\text { function is stimulated. }\end{array}$ & [77] \\
\hline \multirow[t]{2}{*}{ Thiopental } & Suppression of T lymphocyte function. & [78] \\
\hline & $\begin{array}{l}\text { A reduction of platelet tissue factor and TNF production. Inhibits the expression of } \\
\text { lipopolysaccharide-induced tissue factor. }\end{array}$ & [79] \\
\hline
\end{tabular}

$\mathrm{COX}=$ Cyclooxygenase, iNOS=Inducible nitric oxide synthase, NF=Nuclear factor, IL=Interleukin, NK=Natural killer, $P G=$ Prostaglandin, $R O S=$ Reactive oxygen species, $T L R=$ Toll-like receptor, $T N F=$ Tumour necrosis factor

also present due to the sequestration in tissues and the adherence of circulating lymphocytes to the endothelial cells. Glucocorticoids also stimulate the migration of neutrophils from the bone marrow to the bloodstream and attenuate their transit to other compartments, generating neutrophilia with increasing concentrations of mature and immature neutrophils [80]. In cats, the variations in leukocytes are usually greater than in dogs (up to 4 times the reference values), leading to physiologic leukocytosis [81].

In general, pain and surgical stress suppress the immune system and predispose animals to infection, and extended hospital stays because immunosuppression promotes inflammation and delays healing [82]. Figure- 2 shows a schematic summary of the neurobiology of stress related to anesthetic-surgical stimuli.

While all these biological events maintain a close relationship to possible behavioral changes that patients may show during clinical evaluations, no single physiological or behavioral parameter can serve as a specific indicator to raise suspicions that an individual animal is suffering from surgical stress. Although most or all of the responses mentioned above may be present, it is essential to correlate all the neurobiological assessments performed during both the intra- and post-operative periods [82].

\section{Behavioral Changes Associated with a Predominance of Sympathetic Tone that Indicates Hemodynamic Reactivity due to Pain and Surgical Stress}

Pain is the main factor that triggers changes in the neurobiology of stress after surgery since it is responsible for the neuronal and biochemical feedback through mediators such as substance P, bradykinin, histamine, glutamate, potassium ions, and the calcitonin gene-related peptide [11]. These substances, known together as the "inflammatory soup," have been associated with pain or stress in animals, where studies have recognized alterations that can affect the state of alertness and performance of learning and memory [83].

Research has determined that intensive sensory stimulation (i.e., somatic, visual, and acoustic inputs in the brain) activate the locus coeruleus, limbic regions (hypothalamus, hippocampus, and amygdala), and cerebral cortex, causing adaptive responses to acute stress with enhanced neuronal activity due to the excitatory properties of ACTH and CRF that alter periods of vigilance and agitation and results in reactions such as startling, anxiety, fear, and, in some animals, euphoria [11]. Some researchers interpret these behavioral changes in dogs and cats as indicators of stress [10].

The hemodynamic reactivity associated with pain is generated by sympathetic-adrenergic and motor activation. Once the painful impulse reaches the spinal cord, the dorsal horn neurons establish synapses with somatomotor neurons and sympathetic preganglionic neurons. Stimulation of these neurons causes changes in the neurological, cardiovascular, respiratory, digestive, urinary, muscular, and endocrine systems [84]. Behavioral alterations associated with painful processes include temperament, vocalizations, posture, and locomotion, and its manifestation depends on factors such as the species, breed, health, and age $[85,86]$. 
Stimulation of the cardiac, respiratory, and endocrine centers occurs once the nociceptive information reaches the brainstem, thalamus, and hypothalamus. Alterations in the cardiovascular system result from sympathetic activity and release of catecholamines that cause hypertension due to peripheral vasoconstriction, tachycardia, increased myocardial contractility, and systemic vascular resistance. This, in turn, generates a high demand for oxygen and elevated oxygen consumption by the myocardium [84]. An increase of $20 \%$ in the sympathetic tone from the baseline heart rate, respiratory rate, and MAP is usually associated with mild-to-moderate pain. In comparison, a $50 \%$ increase is interpreted as severe pain that requires rescue analgesic therapy [86,87]. In addition, the so-called Virchow triad fosters the onset of thromboembolic phenomena. Likewise, the persistence of peripheral vasoconstriction can generate acidosis due to the low oxygen supply to tissues $[82,87]$.

Changes in respiratory patterns appear after stimulation of the respiratory centers. Diaphragmatic dysfunction and reflex contractures of the thoracoabdominal musculature limit the expansion of the thoracic cavity, raising the risk of respiratory infections and retention of secretions. Hyperventilation initially occurs, but this soon turns into hypoventilation associated with hypoxemia, hypercapnia, tachypnea, and wheezing. In addition, to the increased oxygen demand induced by catecholamines, hypoventilation may worsen respiratory acidosis $[84,88]$.

When nociceptive information reaches the somatosensory cortex, it produces the so-called cortical responses, manifested as behavioral and psychological actions that determine the animal's reaction. This wide variety of signs is usually cited in pain scale evaluations for the clinical recognition of pain or states of surgical stress [84]. In general, the position of the body, facial changes in the eyes, pupils, and orientation of the ears and whiskers, demeanor, vocalizations (such as cries, whimpers, and growls), appetite (hyporexia or anorexia), urination, grooming, and social behavior are considered to assess the level of discomfort and can differ between species [85]. There is a prevalence of antalgic postures in dogs such as "prayer posture", aggression, restriction of movement, star-gazing behavior, excessive licking, crouching, hypervigilance, intermittent vocalization, shivering, and submissive attitude [89]. However, cats tend to be depressed with a hunched posture, muzzle tensed, squinted eyes, ears flattened outwards, whiskers straight and forward, and head below the shoulder line. They also show sudden freezing, nibbling the injured area, tail flicking, hiding at the back of the cage, vocalization when approached (groan, hiss), and guarding behavior with prolonged recumbency $[90,91]$. Decreased pain tolerance can also cause a delay in the growth rate of young animals $[86-88,92]$. Some of the common stress indicators are listed in Table-2 $[84,85,88,89,91]$.

\section{Biomarkers and the Development of Tools to Assess Pain and Surgical Stress}

Several indicators have been described in the literature to determine stress in animals under various circumstances, usually by measuring pain $[93,94]$. The biomarkers most often used are cortisol and glucose levels, two substances involved in the adrenocortical response. However, some studies classify these as non-specific because their secretion and synthesis can be affected by administering drugs (e.g., fentanyl) or other factors, such as anxiety $[15,93,94]$.

In an attempt to design a simple clinical parameter that could correlate physiological reactions with surgical stress, developed a tool that makes it possible to evaluate the variability of heart rate and signs of absolute amplitude from plethysmography, which indicates the degree of tissue perfusion and its relationship to catecholamine, physiological reactions that occur during surgical stress [95]. However, this method has not yet shown high sensitivity or specificity for detecting stress or pain [96]. The pleth variability index (PVI) is a method used to monitor fluid responsiveness and hemodynamic optimization and is associated with tissue perfusion and perioperative serum lactate levels. In dogs undergoing surgery, PVIguided fluid therapy significantly lowered lactate levels [97]. However, between species, its levels are not always consistent with the severity of the process, and

Table-2: Summary of the main physiological, behavioral, and laboratory parameters changes as a result of acute pain and surgical stress $[84,85,88,89,91]$.

\begin{tabular}{lll}
\hline Physiological changes & Behavioral changes & Changes in biochemical parameters \\
\hline Tachycardia & Vocalization & $\downarrow \mathrm{PaO}_{2}$ \\
Hypertension & Look and lick the affected area & $\downarrow \mathrm{PaCO}_{2}$ \\
Cardiac arrhythmias & Alteration of the facial expression & $\downarrow \mathrm{HCO}_{3}$ \\
Tachypnea & Self-mutilation & $\uparrow+\mathrm{H}$ \\
Superficial respiratory pattern & Muscle stiffness or weakness & $\uparrow$ Lactate \\
Pale mucous membranes & Restlessness and anxiety & $\uparrow$ Glucose \\
Mydriasis & Apathy and inactivity & \\
Sialorrhea & Aggression, fear, and depression & \\
Hyperglycemia & Stereotypes & \\
& Anorexia or hyporexia & \\
\hline \hline
\end{tabular}


cats with a slight increment show higher mortality due to the exponential increase with increased compromise rather than the linear fashion observed in dogs [46].

Another study evaluated blood pressure, plasma VP concentrations, and urinary noradrenaline/creatinine levels, but it concluded that, despite evidence of elevated indices for these three parameters, there was no difference in, or relationship to, harmful stimuli, such as the removal of ovaries [20].

Srithunyarat et al. [12] evaluated the association among chromogranin A, catestatin, and vasodilatation in dogs undergoing elective surgery (these are biomarkers associated with stress in humans that have shown high sensitivity). Their results documented significant differences in these three biomarkers' plasma levels after surgery and concluded that these markers could be used effectively to evaluate stress and painful stimuli in dogs subjected to harmful procedures. However, further studies are needed to corroborate their findings.

As described above, evaluations of nociception in anesthetized animals are based not only on detecting hemodynamic reactivity, defined as tachycardia and increased blood pressure but also on changes in respiratory patterns or locomotion. However, such modifications may not be specific to nociception and can be affected by anesthetic agents, clinical condition, and surgery [98]. For this reason, several methods have been proposed to more reliably quantify the nociception/anti-nociception balance by analyzing reflex pathways, pulsed photoplethysmography signals, pupillometry, and heart rate variability (HRV) [99-101].

In human anesthesiology, the analgesia/nociception index, derived from HRV, is an index that reflects a relative parasympathetic tone and is considered a validated tool for detecting intraoperative nociception [102-105]. This technology has been adapted in veterinary medicine as the parasympathetic tone activity (PTA) index to study acute pain in dogs, cats, and horses. Both indices analyze HRV and reflect the sympathovagal balance [106]. Although they can be altered by premedication during surgery, they can predict hemodynamic reactivity [107] and indicate the analgesia/nociception balance [108,109]. A high value would indicate a high parasympathetic tone and the absence of nociception, and a low value would reflect a low parasympathetic tone and potential nociception

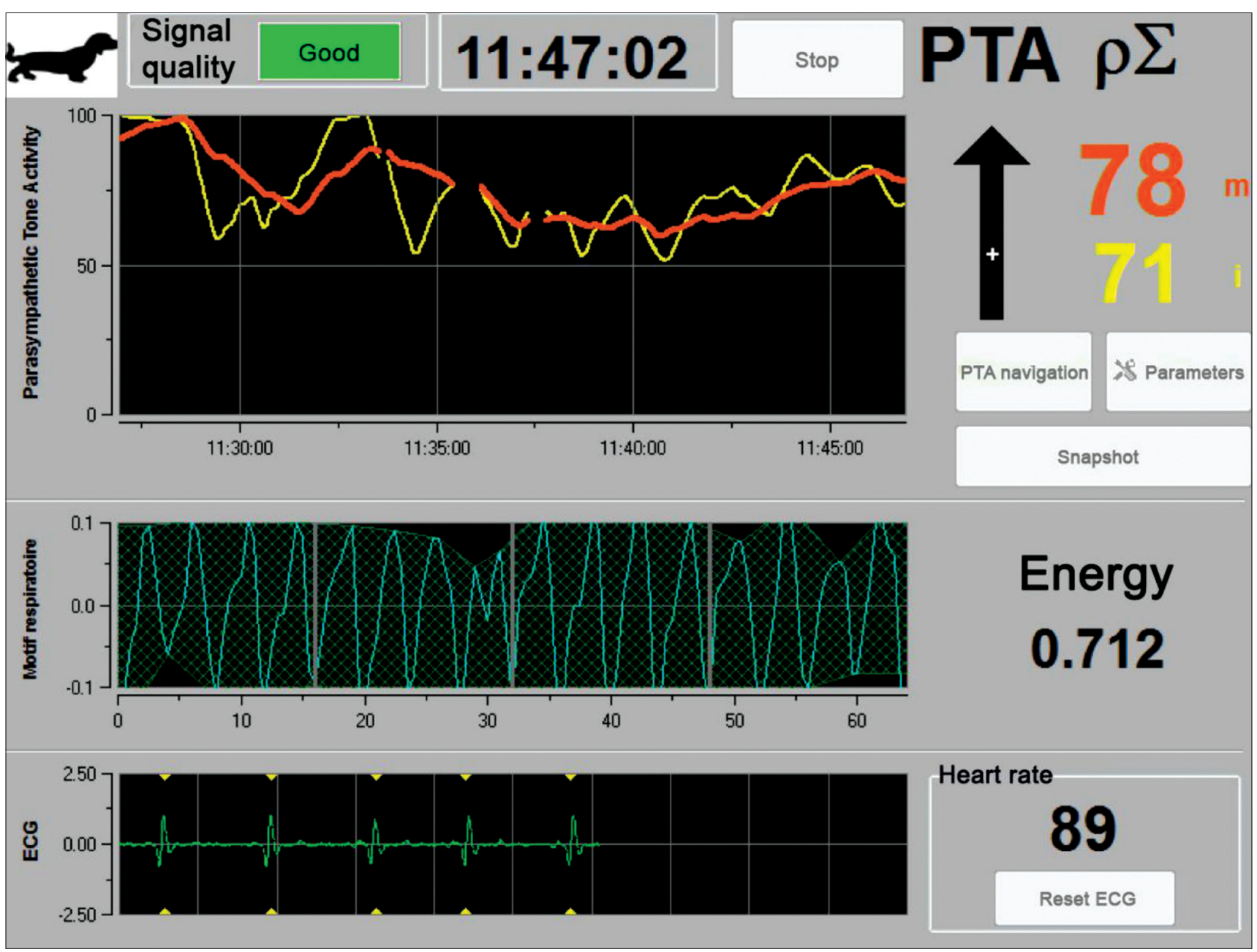

Figure-3: Parasympathetic tone activity index monitoring for the assessment of pain. PTA uses the electrocardiogram signal to evaluate heart rate variability as a non-invasive method for assessing the autonomic nervous system. Highfrequency waves $(0.15-0.5 \mathrm{~Hz})$ are observed in this figure, which are related only to parasympathetic activity. In this case, it was concluded that the patient did not experience pain. 
(Figure-3) [98]. In conscious patients, PTA provided objective scores of the level of stress in cats during physical examination [110].

Furthermore, infrared thermography is another tool that evaluates perioperative stress and analgesia by measuring peripheral tissue microcirculation, which is altered during an acute injury [111]. Spectral entropy in tail clamping and the nociceptive withdrawal reflex in responsive cats are monitors designed to assess intraoperative nociception. However, few studies evaluate the level of surgical influence in animals [112].

As the evidence presented herein shows, we do not yet have a specific biomarker that effectively quantifies the surgical stress or pain that animals perceive; rather, it is necessary to integrate several biomarkers and evaluations to make an overall assessment. The current chemical markers and pain scoring systems have limitations regarding the species, the physiology, the anesthetic protocol, and the observational assessment. Therefore, parameters such as PTA index and infrared thermography could be considered as additional tools for a multimodal and more objective insight into surgical stress and pain for further studies.

\section{Conclusion}

Stress is an adaptive response necessary for a favorable reaction to harmful stimuli through metabolic, endocrine, hemodynamic, behavioral, and immunological mechanisms. However, it is also wellknown that sustained, constant, and uncontrolled states cause unwanted effects during the post-operative recovery phase. Both the veterinary surgeon and anesthesiologist involved must be intimately familiar with all aspects of this complex process to control or, if possible, prevent stress. It is also imperative to acknowledge the absence of a single specific biomarker capable of objectively evaluating the degree of pain or stress in animals. Studies on surgical-anesthetic stress should be carried out using a comprehensive analysis of physiological signs (heart rate, respiratory rate, blood pressure, and temperature) and biochemical markers (cortisol, catecholamines, lactate, glucose, and IL), in addition to the assessment of autonomous responses to noxious stimuli with newly developed tools such as the PTA index or HRV, and behavior-based pain scoring scales. The integration of these parameters could help veterinarians obtain a more accurate evaluation to prevent and manage the neurobiological and behavioral aspects of the perioperative period.

\section{Authors' Contributions}

IHA conceptualized, drafted, and supervised the final version. IHA, EF, and DM contributed to the original draft, data curation, investigation, writing, review, and editing of the manuscript. AEM worked on the methodology, writing, and editing of the review. AC and $\mathrm{AD}$ collected relevant literature, wrote, reviewed, and edited the manuscript. All authors have read and approved the final manuscript.

\section{Acknowledgments}

The authors did not receive any funds for this study.

\section{Competing Interests}

The authors declare that they have no competing interests.

\section{Publisher's Note}

Veterinary World remains neutral with regard to jurisdictional claims in published institutional affiliation.

\section{References}

1. Desborough, J.P. (2000) The stress response to trauma and surgery. Br. J. Anaesth., 85(1): 109-117.

2. Umamaheswaran, S., Dasari, S.K., Yang, P., Lutgendorf, S.K. and Sood, A.K. (2018) Stress, inflammation, and eicosanoids: An emerging perspective. Cancer Metastasis Rev., 37(2-3): 203-211.

3. Kinlein, S.A., Wilson, C.D. and Karatsoreos, I.N. (2015) Dysregulated hypothalamic-pituitary-adrenal axis function contributes to altered endocrine and neurobehavioral responses to acute stress. Front. Psychiatry, 6(3): 31.

4. Fazio, E., Medica, P., Cravana, C., Pupillo, A. and Ferlazoo, A. (2015) Effects of ovariohysterectomy in dogs and cats on adrenocortical, haematological and behavioural parameters. Acta Sci. Vet., 43: 1339.

5. Horta, R.S., Figueiredo, M.S., Lavalle, G.E., Costa, M.P., Cunha, R.M. and Araújo, R.B. (2015) Surgical stress and postoperative complications related to regional and radical mastectomy in dogs. Acta Vet. Scand., 57(1): 1-10.

6. Yuki, K., Matsunami, E., Tazawa, K., Wang, W., DiNardo, J.A. and Koutsogiannaki, S. (2017) Pediatric perioperative stress responses and anesthesia. Transl. Perioper. Pain Med., 2(1): 1-12.

7. Thompson, J.M. and Neugebauer, V. (2017) Amygdala plasticity and pain. Pain Res. Manag., 2017: 8296501.

8. Herman, J.P., McKlveen, J.M., Ghosal, S., Kopp, B., Wulsin, A., Makinson, R., Scheimann, J. and Myers, B. (2016) Regulation of the hypothalamic-pituitary-adrenocortical stress response. Compr. Physiol., 6(2): 603-621.

9. Hennessy, M.B. (2013) Using hypothalamic-pituitary-adrenal measures for assessing and reducing the stress of dogs in shelters: A review. Appl. Anim. Behav. Sci., 149(1-4): 1-12.

10. Protopopova, A. (2016) Effects of sheltering on physiology, immune function, behavior, and the welfare of dogs. Physiol. Behav., 159: 95-103.

11. Muir, W.W. (2009) Pain and stress. In: Gaynor, J.S. and Muir, W.W., editors. Handbook of Veterinary Pain Management. $2^{\text {nd }}$ ed. Mosby Elsevier, Saint Louis. p42-56.

12. Srithunyarat, T., Höglund, O.V., Hagman, R., Olsson, U., Stridsberg, M., Lagerstedt, A. and Pettersson, A. (2016) Catestatin, vasostatin, cortisol, temperature, heart rate, respiratory rate, scores of the short form of the Glasgow composite measure pain scale and visual analog scale for stress and pain behavior in dogs before and after ovariohysterectomy. BMC Res. Notes, 9(1): 381.

13. Anderson, S.L., Duke-Novakovski, T. and Singh, B. (2014) The immune response to anesthesia: Part 1. Vet. Anaesth. Analg., 41(2): 113-126.

14. Skovira, E.J., Behrend, E.N., Martin, L.G., Palmer, L.E., Kemppainen, R.J. and Lee, H.P. (2017) Effect of laparotomy on the pituitary-adrenal axis in dogs. Am. J. Vet. Res., 78(8): 919-925.

15. Nenadović, K., Vučinić, M., Radenković-Damnjanović, B., 
Janković, L., Teodorović, R., Voslarova, E. and Becskei, Z. (2017) Cortisol concentration, pain and sedation scale in free-roaming dogs treated with carprofen after ovariohysterectomy. Vet. World, 10(8): 888-894.

16. Osorio, J.H., Quenán, Y.E. and Giraldo-Jiménez, L. (2015) Lactate and glucose levels in blood plasma of dogs during the first hour of surgery. Vet. Zootec., 9(2): 79-89.

17. Guevara, L.U.M. and De Lille, F.R. (2011) Medicina del Dolor y Paliativa. $2^{\text {nd }}$ ed. Corinter, Mexico.

18. Höglund, O.V., Olsson, K., Hagman, R., Öhlund, M., Olsson, U. and Lagerstedt, A.S. (2011) Comparison of haemodynamic changes during two surgical methods for neutering female dogs. Res. Vet. Sci., 91(1): 159-163.

19. Höglund, O.V., Lövebrant, J., Olsson, U. and Höglund, K. (2016) Blood pressure and heart rate during ovariohysterectomy in pyometra and control dogs: A preliminary investigation. Acta Vet. Scand., 58(1): 1-7.

20. Höglund, O.V., Hagman, R., Olsson, K., Olsson, U. and Lagerstedt, A.S. (2014) Intraoperative changes in blood pressure, heart rate, plasma vasopressin, and urinary noradrenalin during elective ovariohysterectomy in dogs: Repeatability at removal of the $1^{\text {st }}$ and $2^{\text {nd }}$ ovary. Vet. Surg., 43(7): 852-859.

21. Vieira, J.O., Duarte, J.O., Costa-Ferreira, W. and Crestani, C.C. (2018) Influence of pre-existing hypertension on neuroendocrine and cardiovascular changes evoked by chronic stress in female rats. Psychoneuroendocrinology, 97: 111-119.

22. Biondi, B. and Cooper, D.S. (2019) Thyroid hormone suppression therapy. Endocrinol. Metab. Clin. North Am., 48(1): 227-237.

23. Nicolaides, N.C., Kyratzi, E., Lamprokostopoulou, A., Chrousos, G.P. and Charmandari, E. (2015) Stress, the stress system and the role of glucocorticoids. Neuroimmunomodulation, 22(1-2): 6-19.

24. Dimitrov, D., Aminkov, K. and Marinov, G. (2018) Influence of different anesthetics on some physiological parameters and stress markers during and after surgery of a dog. J. Med. Dent. Pract., 5(1): 696-742.

25. Pertovaara, A. (2013) The noradrenergic pain regulation system: A potential target for pain therapy. Eur. $J$. Pharmacol., 716(1-3): 2-7.

26. Kisani, A.I., Tughgba, T. and Elsa, A.T. (2018) Effects of various surgical procedures on biochemical parameters of Nigerian dogs and their clinical implications. Vet. World, 11(7): 909-914.

27. Michelsen, J., Heller, J., Wills, F. and Noble, G.K. (2012) Effect of surgeon experience on postoperative plasma cortisol and C-reactive protein concentrations after ovariohysterectomy in the dog: A randomised trial. Aust. Vet. J., 90(12): 474-478.

28. Stella, J., Croney, C. and Buffington, T. (2013) Effects of stressors on the behavior and physiology of domestic cats. Appl. Anim. Behav. Sci., 143(2-4): 157-163.

29. Vihonen, H., Kuisma, M., Salo, A., Ångerman, S., Pietiläinen, K. and Nurmi, J. (2019) Mechanisms of early glucose regulation disturbance after out-of-hospital cardiopulmonary resuscitation: An explorative prospective study. PLoS One, 14(3): 1-13.

30. Hartmann, C., Radermacher, P., Wepler, M. and Nußbaum, B. (2017) Non-hemodynamic effects of catecholamines. Shock, 48(4): 390-400.

31. Höglund, O.V., Hagman, R. and Stridsberg, M. (2015) Chromogranin A and cortisol at intraoperative repeated noxious stimuli: Surgical stress in a dog model. SAGE Open Med., 3: 1-6.

32. Whirledge, S. and Cidlowski, J.A. (2013) A role for glucocorticoids in stress-impaired reproduction: Beyond the hypothalamus and pituitary. Endocrinology, 154(12): 4450-4468.

33. Alley, J., Diamond, L.M., Lipschitz, D.L. and Grewen, K. (2019) Associations between oxytocin and cortisol reactivity and recovery in response to psychological stress and sexual arousal. Psychoneuroendocrinology, 106: 47-56.

34. Geraghty, A.C. and Kaufer, D. (2015) Glucocorticoid regulation of reproduction. Adv. Exp. Med. Biol., 872: 253-278.

35. Van Nimwegen, S.A., Van Goethem, B.G.J. and Kirpensteijn, J. (2018) A laparoscopic approach for removal of ovarian remnant tissue in 32 dogs. BMC Vet. Res., 14(1): $1-13$.

36. Idowu, O. and Heading, K. (2018) Hypoglycemia in dogs: Causes, management, and diagnosis. Can. Vet. J., 59(6): 642-649.

37. Salvadó, L., Palomer, X., Barroso, E. and Vázquez-Carrera, M. (2015) Targeting endoplasmic reticulum stress in insulin resistance. Trends Endocrinol. Metab., 26(8): 438-448.

38. Gottlieb, S. and Rand, J. (2018) Managing feline diabetes: Current perspectives. Vet. Med. (Auckl), 9: 33-42.

39. Rand, J.S., Kinnaird, E., Baglioni, A., Blackshaw, J. and Priest, J. (2002) Acute stress hyperglycemina in cats is associated with struggling and increased concentrations of lactate and norepinephrine. J. Vet. Intern. Med., 16(2): 123-132.

40. Leininger, S. (2018) Blood glucose management for reducing cardiac surgery infections. Crit. Care Nurs. Q., 41(4): 399-406.

41. Archer, A.E., Von Schulze, A.T. and Geiger, P.C. (2018) Exercise, heat shock proteins and insulin resistance. Philos. Trans. R. Soc. B., 373(1738): 20160529.

42. Cătoi, A.F., Pârvu, A.E., Andreicuț, A.D., Mironiuc, A., Crăciun, A., Cătoi, C. and Pop, I.D. (2018) Metabolically healthy versus unhealthy morbidly obese: Chronic inflammation, nitro-oxidative stress, and insulin resistance. Nutrients, 10(9): 1-11.

43. Sharkey, L.C. and Wellman, M.L. (2015) Use of lactate in small animal clinical practice. Clin. Lab. Med., 35(3): 567-577.

44. Hernández, G., Bellomo, R. and Bekker, J. (2019). The ten pitfalls of lactate clearance in sepsis. Intensive Care Med., 45(1): 82-85.

45. Garcia-Alvarez, M., Marik, P. and Bellomo, R. (2014) Stress hyperlactataemia: Present understanding and controversy. Lancet Diabetes Endocrinol., 2(4): 339-347.

46. Rosenstein, P.G., Tennent-Brown, B.S. and Hughes, D. (2018) Clinical use of plasma lactate concentration. Part 2: Prognostic and diagnostic utility and the clinical management of hyperlactatemia. J. Vet. Emerg. Crit. Care, 28(2): 106-121.

47. Mujika, I. (2017) Quantification of training and competition loads in endurance sports: Methods and applications. Int. J. Sports Physiol. Perform., 12(2): S29-S217.

48. Grocott, M.P., Martin, D.S., Levett, D.Z., McMorrow, R., Windsor, J. and Montgomery, H.E. (2009) Arterial blood gases and oxygen content in climbers on Mount Everest. $N$. Engl. J. Med., 360(2): 140-149.

49. Thrasher, T.N., Chen, H.G. and Keil, L.C. (2000) Arterial baroreceptors control plasma vasopressin responses to graded hypotension in conscious dogs. Am. J. Physiol. Regul. Integr. Comp. Physiol., 278(2): 469-475.

50. Gonzalez, A.A., Salinas-Parra, N., Cifuentes-Araneda, F. and Reyes-Martínez, C. (2020) Vasopressin actions in the kidney renin angiotensin system and its role in hypertension and renal disease. Vitam. Horm., 113: 217-238.

51. Fuentes, D.Z., López, L.S. and Salazar, D.M. (2014) Considerations about the physiological response to surgical stress. Rev. Cuba. Anestesiol. Reanim., 13(2): 136-146.

52. Alazawi, W., Pirmadjid, N., Lahiri, R. and Bhattacharya, S. (2016) Inflammatory and immune responses to surgery and their clinical impact. Ann. Surg., 264(1): 73-80.

53. Palmer, J., Pandit, V., Zeeshan, M., Kulvatunyou, N., Hamidi, M., Hanna, K., Fain, M., Nikolich-Zugich, J., Zakaria, E. and Joseph, B. (2019) The acute inflammatory response after trauma is heightened by frailty: A prospective evaluation of inflammatory and endocrine system 
alterations in frailty. J. Trauma Acute Care Surg., 87(1): 54-60.

54. Dinarello, C.A. (2018) Overview of the IL-1 family in innate inflammation and acquired immunity. Immunol. Rev., 281(1): 8-27.

55. Srinivasan, L., Harris, M. and Kilpatrick, L.E. (2017) Cytokines and inflammatory response in the fetus and neonate. In: Polin, R.A., Abman, S.H., Rowitch, D.H., Benitz, W.E. and Fox, W.W., editors. Fetal and Neonatal Physiology. $5^{\text {th }}$ edition. Elsevier, Philadelphia, PA. p1241-1254.

56. Bown, M.J., Nicholson, M.L., Bell, P.R. and Sayers, R.D. (2001) Cytokines and inflammatory pathways in the pathogenesis of multiple organ failure following abdominal aortic aneurysm repair. Eur. J. Vasc. Endovasc. Surg., 22(6): 485-495.

57. Narazaki, M. and Kishimoto, T. (2018) The two-faced cytokine IL-6 in host defense and diseases. Int. J. Mol. Sci., 19(11): 3528 .

58. Anderson, S.L., Duke-Novakovski, T. and Singh, B. (2014) The immune response to anesthesia: Part 2 sedatives, opioids, and injectable anesthetic agents. Vet. Anaesth. Analg., 41(6): 553-566.

59. Sandersen, C., Mouithys-Mickalad, A., de la Rebière, G., Deby, G., Serteyn, D. and Franck, T. (2011) Modulating effects of acepromazine on the reactive oxygen species production by stimulated equine neutrophils. Vet. Anaesth. Analg., 38(2): 83-93.

60. Wu, Y., Liu, Y., Huang, H., Zhu, Y., Zhang, Y., Lu, F., Zhou, C., Huang, L., Li, X. and Zhou, C. (2013) Dexmedetomidine inhibits inflammatory reaction in lung tissues of septic rats by suppressing TLR4/NF-jB pathway. Mediators Inflamm., 2013: 562154.

61. Chen, C., Zhang, Z., Chen, K., Zhang, F., Peng, M. and Wang, Y. (2014) Dexmedetomidine regulates inflammatory molecules contributing to ventilator-induced lung injury in dogs. J. Surg. Res., 187(1): 211-218.

62. Zhang, J., Peng, K., Zhang, J., Meng, X. and Ji, F. (2017) Dexmedetomidine preconditioning may attenuate myocardial ischemia/reperfusion injury by down-regulating the HMGB1-TLR4-MyD88-NF-kB signaling pathway. PLoS One, 12(2): 1-15.

63. Jafarzadeh, A., Hadavi, M., Hassanshahi, G., Rezaeian, M. and Vazirinejad, R. (2020) General anesthetics on immune system cytokines: A narrative review article. Anesth. Pain Med., 10(4): e103033.

64. Li, Y., Shen, R., Wen, G., Ding, R., Du, A., Zhou, J., Dong, Z., Ren, X., Yao, H., Zhao, R., Zhang, G., Lu, Y. and $\mathrm{Wu}, \mathrm{X}$. (2017) Effects of ketamine on levels of inflammatory cytokines IL-6, IL-1 $\beta$, and TNF- in the hippocampus of mice following acute or chronic administration. Front. Pharmacol., 8: 139.

65. Alcott, C.J., Sponseller, B.A., Wong, D.M., Davis, J.L., Soliman, A.M., Wang, C. and Hsu, W. (2011) Clinical and immunomodulating effects of ketamine in horses with experimental endotoxemia. J. Vet. Intern. Med., 25(4): 934-943.

66. Liu, F.L., Chen, T.L. and Chen, R.M. (2012) Mechanisms of ketamine-induced immunosuppression. Acta Anaesthesiol. Taiwan., 50(4): 172-177.

67. Ferreira, C.F., Macedo, R.P.R. and Pelosi, P. (2017) Antiinflammatory properties of anesthetic agents. Crit. Care, 21(1): 67.

68. Maeda, K., Sakonju, I., Kumakura, A., Tomizawa, Z., Kakuta, T., Shimamura, S., Okano, S. and Takase, K. (2010) Effects of lidocaine hydrochloride on canine granulocytes, granulocyte $\mathrm{CD} 11 \mathrm{~b}$ expression and reactive oxygen species production. J. Vet. Med. Sci., 72(2): 141-147.

69. Ploppa, A., Kiefer, R.T., Haverstick, D.M., Groves, D.S., Unertl, K.E. and Durieux, M.E. (2010) Local anesthetic effects on human neutrophil priming and activation. Reg. Anesth. Pain Med., 35(1): 45-50.
70. Smith, M.A., Hibino, M., Falcione, B.A., Eichinger, K.K., Patel, R. and Empey, K.M. (2015) Immunosuppressive aspects of analgesics and sedatives used in mechanically ventilated patients: An underappreciated risk factor for the development of ventilator-associated pneumonia in critically ill patients. Ann. Pharmacother., 48(1): 77-85.

71. Kim, H., Myung, S., Park, Y.C. and Park, B. (2017) Use of benzodiazepine and risk of cancer: A meta-analysis of observational studies. Int. J. Cancer, 140(3): 513-525.

72. Kim, S.N., Son, S.C., Lee, S.M., Kim, C.S., Yoo, D.G., Lee, S.K., Hur, G.M., Park, J.B. and Jeon, B.H. (2006) Midazolam inhibits proinflammatory mediators in the lipopolysaccharide-activated macrophage. Anesthesiology, 105(1): 105-110.

73. Bimonte, S., Barbieri, A., Palma, G. and Arra, C. (2013) The role of morphine in animal models of human cancer: Does morphine promote or inhibit the tumor growth? BioMed Res. Int., 2013: 258141.

74. Brown, J.N., Ortiz, G.M., Angel, T.E., Jacobs, J.M., Gritsenko, M., Chan, E.Y., Purdy, D.E., Murnane, R.D., Larsen, K., Palermo, R.E., Shukla, A.K., Clauss, T.R., Katze, M.G., McCune, J.M. and Smith, R.D. (2012) Morphine produces immunosuppressive effects in nonhuman primates at the proteomic and cellular levels. Mol. Cell. Proteomics, 11(9): 605-618.

75. Roy, S., Ninkovic, J., Banerjee, S., Charboneau, R.G., Das, S., Dutta, R., Kirchner, V.V., Koodie, L., Ma, J., Meng, J. and Barke, R.A. (2011) Opioid drug abuse and modulation of immune function: Consequences in the susceptibility to opportunistic infections. J. Neuroimmune Pharmacol., 6(4): 442-465.

76. Sanders, R.D., Hussell, T. and Maze, M. (2011) Sedation and immunomodulation. Anesthesiol. Clin., 29(4): 687-706.

77. Inada, T., Kubo, K., Ueshima, H. and Shingu, K. (2011) Intravenous anesthetic propofol suppresses prostaglandin E2 production in murine dendritic cells. J. Immunotoxicol., 8(4): 359-366.

78. Dogan, Z., Yuzbasioglu, M.F., Kurutas, E.B., Yildiz, H., Coskuner, I., Senoglu, N., Oksuz, H. and Bülbüloglu, E. (2010) Thiopental improves renal ischemia-reperfusion injury. Ren. Fail., 32(3): 391-395.

79. Kim, R. (2018) Effects of surgery and anesthetic choice on immunosuppression and cancer recurrence. J. Transl. Med., 16(1): 1-13.

80. Kritsepi-Konstantinou, M. and Oikonomidis, I.L. (2016) The interpretation of leukogram in dog and cat. Hell. J. Comp. Anim. Med., 5(2): 62-68.

81. Fam, A.L.P., Rocha, R.M.V., Pimpão, C.T. and Cruz, M.A. (2010) Alterations on leukogram of domestic felines (Felis catus) due to acute chronic stress. Rev. Acad. Ciênc. Agrár. Ambient., 8(3): 299-306.

82. Thomas, J.A. and Lerche, P. (2017) Anesthesia and Analgesia for Veterinary Technicians. $5^{\text {th }}$ ed. Mosby Elsevier, Saint Louis.

83. Segelcke, D., Pradier, B. and Pogatzki-Zahn, E. (2019) Advances in assessment of pain behaviors and mechanism of postoperative pain models. Curr. Opin. Physiol., 11: 85-92.

84. Pérez, T. and Castañeda, J. (2012) Pathophysiology of acute pain: Cardiovascular, respiratory alterations and of other systems and organs. Rev. Cuba. Anestesiol. Reanim., 11(1): 19-26.

85. Reid, J., Nolan, A.N. and Scott, E.M. (2018) Measuring pain in dogs and cats using structured behavioural observation. Vet. J., 236: 72-79.

86. Bufalari, A., Adami, C., Angeli, G. and Short, C.E. (2007) Pain assessment in animals. Vet. Res. Commun., 31(1): $55-58$.

87. Buckenmaier, C. and Mahoney, P.F. (2015) Combat Anesthesia: The First 24 Hours. $1^{\text {st }}$ ed. Office of the Surgeon General, Houston.

88. Mathews, K.A., Kronen, P.W., Lascelles, D., Nolan, A., 
Robertson, S., Steagall, P., Wright, B. and Yamashita, K. (2014) Guidelines for recognition, assessment and treatment of pain. J. Small Anim. Pract., 55(6): E10-68.

89. Mills, D.S., Demontigny-Bédard, I., Gruen, M., Klinck, M.P., McPeake, K.J., Barcelos, A.M., Hewinson, L., Haevermaet, H.V., Denenberg, S., Hauser, H., Koch, C., Ballantyne, K., Wilson, C., Mathkari, C.V., Pounder, J., García, E., Darder, P., Fatjó, J. and Levine, E. (2020) Pain and problem behavior in cats and dogs. Animals, 10(2): 318 .

90. Brondani, J.T., Luna, S.P.L. and Padovani, C.R. (2011) Refinement and initial validation of a multidimensional composite scale for use in assessing acute postoperative pain in cats. Am. J. Vet. Res., 72(2): 174-183.

91. Steagall, P.V. and Monteiro, B.P. (2019) Acute pain in cats: Recent advances in clinical assessment. J. Feline Med. Surg., 21(1): 25-34.

92. Lezama-García, K., Orihuela, A., Olmos-Hernández, A., Reyes-Long, S. and Mota-Rojas, D. (2019) Facial expressions and emotions in domestic animals. CAB Rev., 14(28): $1-12$.

93. Romano, M., Portela, D.A., Breghi, G. and Otero, P.E. (2016) Stress-related biomarkers in dogs administered regional anesthesia or fentanyl for analgesia during stifle surgery. Vet. Anaesth. Analg., 43(1): 44-54.

94. Benson, G.J., Grubb, T.L., Neff-Davis, C., Olson, W.A., Thurmon, J.C., Lindner, D.L., Tranquilli, W.J. and Vanio, O. (2000) Perioperative stress response in the dog: Effect of pre-emptive administration of medetomidine. Vet. Surg., 29(1): 85-91.

95. Huiku, M., Uutela, K., Van Gils, M., Korhonen, I., Kymäläinen, M., Meriläinen, P., Paloheimo, M., Rantanen, M., Takala, P., Viertiö-Oja, H. and YliHankala, A. (2007) Assessment of surgical stress during general anesthesia. Br. J. Anaesth., 98(4): 447-455.

96. Chen, X., Thee, C., Gruenewald, M., Wnent, J., Illies, C., Hoecker, J., Hanss, R., Steinfath, M. and Bein, B. (2010) Comparison of surgical stress index-guided analgesia with standard clinical practice during routine general anesthesia: A pilot study. Anesthesiology, 112(5): 1175-1183.

97. Hu, C.H., Hsu, T.H., Chen, K.S., Lee, W.M. and Wang, H.C. (2018) Pleth variability index-guided fluid therapy lowers postoperative lactate levels in dogs undergoing elective abdominal surgery: A randomized controlled trial. Taiwan Vet. J., 44(1): 7-14.

98. Mansour, C., Merlin, T., Bonnet-Garin, J.M., Chaaya, R., Mocci, R., Conde, R.C., Allaouchiche, B., Boselli, E. and Junot, S. (2017) Evaluation of the parasympathetic tone Activity (PTA) index to assess the analgesia/nociception balance in anaesthetised dogs. Res. Vet. Sci., 115: 271-277.

99. Gruenewald, M. and Ilies, C. (2013) Monitoring the nociception-anti-nociception balance. Best Pract. Res. Clin. Anaesthesiol., 27(2): 235-247.

100. Boselli, E., Bouvet, L. and Allaouchiche, B. (2015) Analgesia monitoring using analgesia/nociception index: Results of clinical studies in awake and anesthetized patients. Prat. Anesth. Reanim., 19(2): 78-86.

101. De Jonckheere, J., Bonhomme, V., Jeanne, M., Boselli, E.,
Gruenewald, M., Logier, R. and Richebé, P. (2015) Physiological signal processing for individualized anti-nociception management during general anesthesia: A review. Yearb. Med. Inform., 10(1): 95-101.

102. De Jonckheere, J., Delecroix, M., Jeanne, M., Keribedj, A., Couturier, N. and Logier, R. (2013) Automated analgesic drugs delivery guided by vagal tone evaluation: Interest of the analgesia nociception index (ANI). Annu. Int. Conf. Proc. IEEE. Eng. Med. Biol. Soc., 2013: 1952-1955.

103. Jeanne, M., Delecroix, M., De Jonckheere, J., Keribedj, A., Logier, R. and Tavernier, B. (2014) Variations of the analgesia nociception index during propofol anesthesia for total knee replacement. Clin. J. Pain., 30(12): 1084-1088.

104. Ledowski, T., Averhoff, L., Tiong, WS. and Lee, C. (2014) Analgesia nociception index (ANI) to predict intraoperative haemodynamic changes: Results of a pilot investigation. Acta Anaesthesiol. Scand., 58(1): 74-79.

105. Boselli, E., Bouvet, L., Bégou, G., Torkmani, S. and Allaouchiche, B. (2015) Prediction of hemodynamic reactivity during total intravenous anesthesia for suspension laryngoscopy using analgesia/nociception index (ANI): A prospective observational study. Minerva Anestesiol., 81(3): 288-297.

106. Hernández-Avalos, I., Mota-Rojas, D., Mora-Medina, P., Martínez-Burnes, J., Casas, A.A., Verduzco-Mendoza, A., Lezama-García, K. and Olmos-Hernández, A. (2019) Review of different methods used for clinical recognition and assessment of pain in dogs and cats. Int. J. Vet. Sci. Med., 7(1): 43-54.

107. Mansour, C., El Hachem, N., Jamous, P., Saade, G., Boselli, E., Allaouchiche, B., Bonnet, J., Junot, S. and Chaaya, R. (2020) Performance of the parasympathetic tone activity (PTA) index to assess the intraoperative nociception using different premedication drugs in anaesthetised dogs. Int. J. Vet. Sci. Med., 8(1): 49-55.

108. Logier, R., Jeanne, M., Tavernier, B. and De Jonckheere, J. (2006) Pain/analgesia evaluation using heart rate variability analysis. Conf. Proc. IEEE Eng. Med. Biol. Soc., 2006: 4303-4306.

109. Ledowski, T., Tiong, W.S., Lee, C., Wong, B., Fiori, T. and Parker, N. (2013) Analgesia nociception index: Evaluation as a new parameter for acute postoperative pain. $B r . J$. Anaesth., 111(4): 627-629.

110. Romero, N.C., Flores, O.A., Heredia, C.R., Miranda, C.L., Reyes, C.L. and Marczuk, D.M. (2020) Evaluation of the effect of feliway on parameters of parasympathetic activity in cats. Int. J. Curr. Adv. Res., 9(7): 22682-22685.

111. Casas-Alvarado, A., Mota-Rojas, D., Hernández-Avalos, I., Mora-Medina, P., Olmos-Hernández, A., VerduzcoMendoza, A., Reyes-Sotelo, B. and Martínez-Burnes, J. (2020) Advances in infrared thermography: Surgical aspects, vascular changes, and pain monitoring in veterinary medicine. J. Therm. Biol., 92:102664.

112. Ruíz-López, P., Domínguez, J.M. and Del Mar, G.M. (2020) Intraoperative nociception-antinociception monitors: A review from the veterinary perspective. Vet. Anaesth. Analg., 47(2): 152-159. 